\title{
Attainment of the Fifth Millennium Development Goal: Utopia or Reality Based on Trends in Maternal Mortality in 12 Years in Two Regional Hospitals in Fako Division, Cameroon? A Retrospective Study
}

\author{
Gregory Edie Halle Ekane ${ }^{1}$, Thomas Egbe Obinchemti ${ }^{1}$, Charlotte Nguefack Tchente ${ }^{2}$, \\ Lydia Kahgomia Fokunang3, Theophile Nana Njamen', Ndamezie Nkafu Bechem ${ }^{4}$, \\ Martin Mafany Njie' ${ }^{1}$, Daniel Latum ${ }^{5}$ \\ ${ }^{1}$ Department of Surgery and Gynecology/Obstetrics, Faculty of Health Sciences, University of Buea, \\ Buea, Cameroon \\ ${ }^{2}$ Department of Obstetrics and Gynecology, Douala General Hospital, Douala, Cameroon \\ ${ }^{3}$ Department of Gynecology and Obstetrics, Regional Hospital Buea, Buea, Cameroon \\ ${ }^{4}$ Department of Obstetrics and Gynecology, Limbe Regional Hospital, Limbe, Cameroon \\ ${ }^{5}$ Department of Public and Community Health, University of Yaoundé 1, Yaoundé, Cameroon \\ Email: "hallegregory@yahoo.fr
}

Received 20 June 2014; revised 18 July 2014; accepted 15 August 2014

Copyright $@ 2014$ by authors and Scientific Research Publishing Inc.

This work is licensed under the Creative Commons Attribution International License (CC BY). http://creativecommons.org/licenses/by/4.0/

(c) (i) Open Access

\section{Abstract}

Introduction: According to WHO, globally an estimated 585,000 women die each year from complications of pregnancy and childbirth. One of the targets of Millennium Development Goal 5 (MDG 5 ) is to reduce maternal mortality by three quarters of the 1999 value by the year 2015 . However, three years to 2015 , very little is known on the trends in maternal mortality ratio, causes of maternal deaths and their associated factors in the Tiko Cottage Hospital (TCH) and Limbe Regional Hospital (LRH) in the South-West Region, Cameroon. Methods: This was a retrospective, analytical cross-sectional study that was carried out from $1^{\text {st }}$ January 2000 to December 2012. After obtaining ethical clearance, the records of cases of maternal deaths and a reference group of women who survived after a pregnancy during the same period were carefully reviewed. The data were analyzed with SPSS 10 and EPI 3.5.1. Results: There were 14,480 live births and 132 maternal deaths during the study period, giving an adjusted Maternal Mortality Ratio (MMR) of 892/100,000 live births. Patients' age ranged from 15 - 40 years (SD 2.3). We observed a downwards trend of Ma-

*Corresponding author.

How to cite this paper: Halle Ekane, G.E., Obinchemti, T.E., Tchente, C.N., Fokunang, L.K., Njamen, T.N., Bechem, N.N., Njie, M.M. and Latum, D. (2014) Attainment of the Fifth Millennium Development Goal: Utopia or Reality Based on Trends in Maternal Mortality in 12 Years in Two Regional Hospitals in Fako Division, Cameroon? A Retrospective Study. Open Journal of Obstetrics and Gynecology, 4, 771-781. http://dx.doi.org/10.4236/ojog.2014.413107 
ternal Mortality Ratio (MMR). Seventy-eight percent of the maternal deaths were due to direct causes. The triad of hemorrhage $(54.5 \%)$, abortions $(17.4 \%)$, and eclampsia $(10.6 \%)$ was the leading cause of death. HIV-related complications and hepatitis constituted the main indirect causes of maternal death. In $\mathbf{8 5 . 4 \%}$ of cases, maternal deaths were avoidable. Lack of blood for transfusion and late referral of cases were the main avoidable factors. Patients less than 35 years $(p=0.01)$, no antenatal care (ANC) $(p=0.001)$, unemployment $[O R=1.52 ; 95 \%$ CI: $(1.38-48.28) ; p$ $=0.02]$ were significantly associated with maternal deaths while grand multiparity $[O R=1.20 ; 95 \%$ CI (0.30 - 4.86); $p=0.79]$, marital status [OR = 1.20; 95\% CI: $(0.70-2.07) ; p=0.51]$ and education level were not significantly associated with maternal deaths. Conclusion: The trend shows that there was no appreciable decline in maternal mortality, implying that attaining the objectives of MDG 5 is very unlikely. Therefore, to meet the MDG 5 target, we recommend that, there should be amelioration towards obstetric emergencies care and health education by health care providers.

\section{Keywords}

\section{Maternal Mortality Ratio, Causes, Trends, MDG 5, South West Region}

\section{Introduction}

Though Sub-Saharan Africa accounts for only 12\% of the world's population, 99\% of maternal deaths occur in this region. Furthermore, 25\% to 30\% of deaths of women of reproductive age are attributable to pregnancy and its complications [1] [2]. Many maternal deaths are preventable, if quality antenatal care (ANC) is provided and rational obstetrical decisions are taken promptly [3]. The main causes of maternal death are post-partum hemorrhage, sepsis and hypertensive disorders in pregnancy [4]. Cameroon being part of Sub-Saharan Africa is no exception to this high death toll with an estimated increase in maternal mortality ratio from 430 to 1000 deaths per 100,000 live births between 1999 and 2010 [5].

Many geographical and periodic variations have been observed in the past ten years with MMR values ranging between 33 and 1266.3 per 100,000 live births [6] [7].

Reduction in maternal deaths by $75 \%$ in 2015 is a cardinal target of the Millennium Development Goals [8]. However, with less than two years before the year targeted for realization of a two-thirds reduction in maternal mortality, Cameroon's maternal mortality figures remain unacceptably high with an adjusted MMR of 1000 per 100,000 live births in 2008 [9].

Periodic obstetric audit is vital for any health system that hopes to provide adequate care for women and their offsprings. It is through such analysis that improvement in health care can be brought about by guided planning. This study aimed at elucidating the trends in maternal mortality ratio, causes of maternal deaths and their associated factors in the Tiko Cottage Hospital (TCH) and Limbe Regional Hospital (LRH) in the South-West Region, Cameroon.

\section{Methods}

The study was carried out in the Limbe and Tiko health districts with estimated populations of 128,275 and 120,100 inhabitants respectively in the South West Region of Cameroon. Ethics approval was obtained from the Institutional Review Board of the Faculty of Health Sciences, University of Buea and the chief medical officers of the aforementioned hospitals. The LRH and TCH where the study was carried out, have obstetrics and gynecology units each headed by an obstetrician, labor wards, maternity wards, facilities for blood transfusion and theaters. These hospitals cover the health needs of most of the population in the districts and complicated cases from health centers are referred to these facilities.

The cases were records of 132 maternal deaths that occurred from $1^{\text {st }}$ January 2000 to $31^{\text {st }}$ December 2012 based on the ICD-10 definition that is, the death of women while pregnant, or within 42 days of termination of pregnancy, from any cause related to or aggravated by pregnancy and its management irrespective of its duration and site, but not from accidental causes were reviewed [10]. The records of 264 women; the normal deliveries preceding and the one that occurred during the same period (shift) after the maternal death were chosen as the 
reference population. All live births that occurred during the study period were also recorded.

Data was collected using a pre-tested questionnaire by medical students. An observation sheet was also used to note any complementary information which could be used to explain the cause of a maternal death that was not found in the questionnaire.

\section{Statistical Analysis}

The data was coded to ensure confidentiality and analyzed using EPI info 3.5.1, STATA 10.0. A p-value less than 0.05 was considered statistically significant.

In describing the socio-demographic and obstetric characteristics of cases and the reference group, measures of central tendencies like mean and median were used for numeric variables. For categorical data, frequencies were computed. Based on the ICD 10 definition [10], the causes for maternal deaths were divided into two groups: direct and indirect causes chi-squared, p-values and odds ratio were used to determine the strength of the association. A bivariate logistic regression model was built to determine the association between the stated characteristics and maternal mortality.

\section{Results}

There were 14,480 live births (6405 live births in TCH and 8075 live births in LRH) and 132 maternal deaths, 46 and 86 in the TCH and LRH hospitals during the period of study giving an adjusted MMR of 718 and 1065 per 100,000 live births respectively. The average MMR for both hospitals was 892 per 100,000 live births. Sixty-seven patients were referred from other hospital or health centres accounted for $50.8 \%$ of the maternal deaths. The direct causes and indirect causes of maternal death had MMR of 662 and 110 per 100,000 live births respectively.

There was much yearly variation in the number of maternal deaths as shown in Table 1.

The trend of maternal mortality with the highest MMR occurring in 2001 and 2002 (1543.2 and 1502.2 deaths per 100,000 live births respectively). MMRs were lowest in 2010 and 2007 (283.9 and 304 deaths per 100,000 live births respectively). There was a progressive increase in the number of live births with highest values in 2010 and 2011.

There was an overall decrease in maternal mortality over the years with an annual decrease of 0.459 maternal deaths per 100,000 live births until 2007, Figure 1.

\section{Table 1. Yearly distribution of maternal deaths and adjusted MMR in Limbe Regional Hospital and CDC Cottage Hospital.}

\begin{tabular}{cccc}
\hline Year & Number of live births & Number of maternal deaths & Ratio/100,000 \\
\hline 2000 & 895 & 11 & 1116.6 \\
2001 & 972 & 15 & 1543.2 \\
2002 & 932 & 14 & 1502.2 \\
2003 & 983 & 12 & 1220.8 \\
2004 & 1013 & 9 & 888.5 \\
2005 & 1075 & 13 & 1209.3 \\
2006 & 1078 & 11 & 1020.4 \\
2007 & 987 & 3 & 304.0 \\
2008 & 1082 & 10 & 924.2 \\
2009 & 1356 & 9 & 663.7 \\
2010 & 1409 & 4 & 283.9 \\
2011 & 1424 & 9 & 632.0 \\
2012 & 1184 & 12 & 1013.5 \\
Total & 11,480 & 132 & 892 \\
\hline
\end{tabular}


The direct obstetrical causes accounted for 102 (77.3\%) of all maternal deaths. Hemorrhage was the leading cause maternal deaths 72 (54.5\%), abortion 23 (17.4\%), and eclampsia 14 (10.6\%). There were 17 (12.9\%) indirect causes of maternal deaths. HIV complications and Hepatitis were the leading indirect causes of maternal deaths in 7 (5.3\%) and 3 (2.3\%). In 12 (9.1\%) of cases, the cause of death was unknown. Most of the diagnoses were all made on clinical grounds, Table 2.

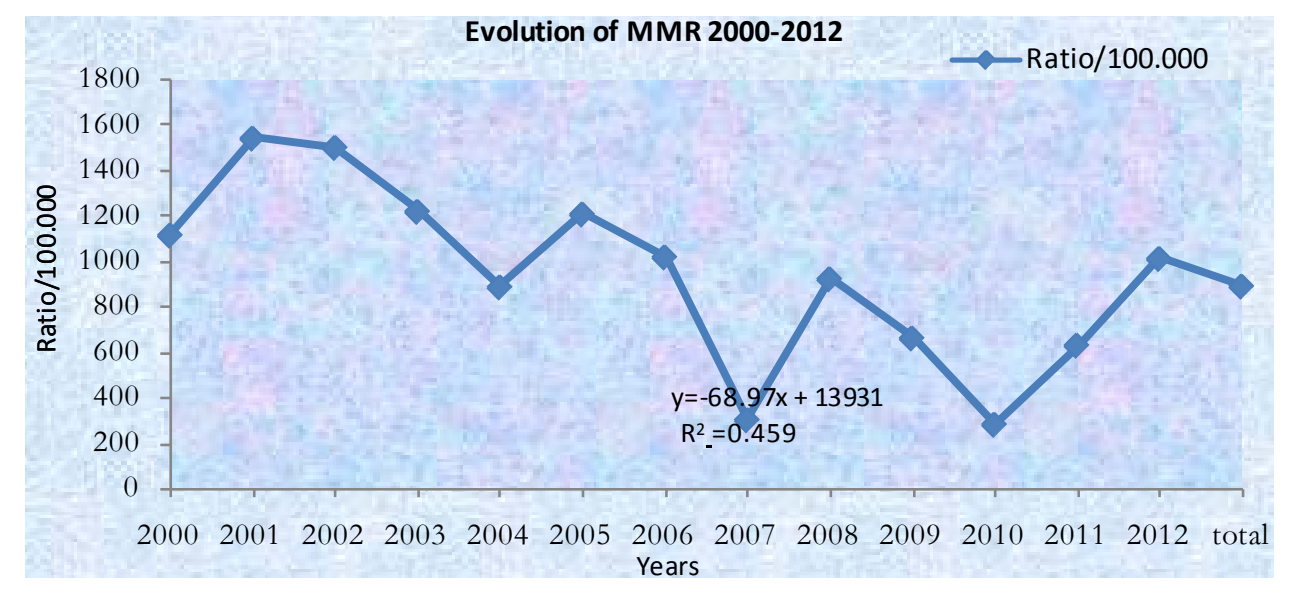

Figure 1. Trend of adjusted maternal mortality ratios.

Table 2. The causes of maternal deaths are depicted.

\begin{tabular}{|c|c|c|}
\hline Causes of Death & Number of deaths & $\%$ of total deaths \\
\hline \multicolumn{3}{|l|}{ Direct causes: } \\
\hline \multicolumn{3}{|l|}{ Antepartum hemorrhage } \\
\hline Abortion & 23 & 17.3 \\
\hline Uterine rupture (antepartun and intrapartum) & 8 & 6.1 \\
\hline Abruptio placenta & 3 & 2.1 \\
\hline Ectopic pregnancy & 2 & 1.4 \\
\hline \multicolumn{3}{|l|}{ Postpartum hemorrhage } \\
\hline Uterine atony & 18 & 13.4 \\
\hline Placenta retention & 11 & 8.1 \\
\hline Cervical lacerations & 4 & 2.9 \\
\hline Retained products & 3 & 2.0 \\
\hline \multicolumn{3}{|l|}{ Sepsis } \\
\hline Post abortal sepsis & 7 & 5.5 \\
\hline Post operative sepsis & 4 & 2.9 \\
\hline Pueperal sepsis & 2 & 1.4 \\
\hline Eclampsia & 14 & 10.5 \\
\hline Anesthesia & 3 & 2.2 \\
\hline Prolonged labour & 1 & 0.7 \\
\hline \multicolumn{3}{|l|}{ Indirect causes: } \\
\hline HIV & 7 & 5.2 \\
\hline Hepatitis & 3 & 2.2 \\
\hline Anemia & 3 & 2.2 \\
\hline Malaria & 2 & 1.4 \\
\hline Intestinal occlusion & 1 & 0.7 \\
\hline Sickle cell & 1 & 0.7 \\
\hline Unknown: & 12 & 8.9 \\
\hline TOTAL & 132 & 100 \\
\hline
\end{tabular}


The socio-demographic and obstetric characteristics of the study population are shown in Tables 3-8.

The ages ranged from 15 - 40 years, mean was $26.5 \pm 6.2$ years for cases. The mean age for reference population was $28.1 \pm 2.1$ years with a range of 17 - 44 years. Most maternal deaths occurred between 20 - 34 years, Table 3.

Parity ranged from 0 - 6 among cases with a mean of $2.16 \pm 1.67$. Women delivering their first babies were the most represented. They constituted $36.4 \%$ of cases and $40.9 \%$ of the reference population, Table 4 . The relationship between parity and maternal mortality was statistically significant.

Table 3. Maternal mortality and age.

\begin{tabular}{ccccc}
\hline Age in years & Number of deaths & Percentage & Reference population & Percentage \\
\hline $15-19$ & 16 & 12.1 & 7 & 2.7 \\
$20-24$ & 36 & 27.3 & 79 & 29.9 \\
$25-29$ & 37 & 28.0 & 99 & 37.5 \\
$30-34$ & 22 & 16.7 & 43 & 18.3 \\
$35-39$ & 14 & 10.6 & 16 & 6.8 \\
$\geq 40$ & 5 & 3.8 & 2 & 0.7 \\
No age & 2 & 1.5 & 264 & 100 \\
Total & 132 & 100 & \\
\hline
\end{tabular}

p-value $<0.05$ is statistically significant.

Table 4. Maternal mortality and parity.

\begin{tabular}{cccccc}
\hline Parity & Number of deaths & Percentage & Controls reference population & Percentage & p-value \\
\hline 0 & 12 & 9.1 & 0.0 & 0.0 & 0.0004 \\
1 & 48 & 36.4 & 108 & 24.6 \\
2 & 22 & 16.7 & 65 & 14.7 \\
3 & 15 & 11.4 & 39 & 11.4 \\
4 & 12 & 9.1 & 30 & 8.3 \\
Unknown & 17 & 12.8 & 22 & 0.0 \\
Total & 6 & 4.5 & 0 & 100 \\
\hline
\end{tabular}

Table 5. Maternal mortality and marital status.

\begin{tabular}{cccccc}
\hline Marital Status & Number who died & Percentage & Reference population & Percentage & p-value \\
\hline Married & 78 & 59.1 & 191 & 72.3 & 0.0003 \\
Single & 42 & 31.8 & 73 & 0.0 \\
Widow & 3 & 2.3 & 0.0 & 0.0 \\
Unknown & 9 & 6.8 & 0.0 & 100 \\
Total & 132 & 100 & 264 & 0.7 \\
\hline
\end{tabular}


Table 6. Maternal mortality and level of education.

\begin{tabular}{|c|c|c|c|c|c|}
\hline Level of education & Number who died & Percentage & Reference population & Percentage & p-value \\
\hline Primary & 28 & 21.2 & 64 & 24.2 & 0.2095 \\
\hline Secondary ${ }^{*}$ & 19 & 14.4 & 33 & 12.5 & \\
\hline University & 0.0 & 0.0 & 0.0 & 0.0 & \\
\hline Professional school & 5 & 3.8 & 0.0 & 0.0 & \\
\hline Unknown & 80 & 60.6 & 167 & 63.3 & \\
\hline Total & 132 & 100 & 264 & 100 & \\
\hline
\end{tabular}

* Includes women who completed secondary or high school.

Table 7. Maternal mortality and antenatal care (ANC).

\begin{tabular}{cccccc}
\hline Attendance & Cases $^{*}$ & $\%$ & Reference population & $\%$ & p-value \\
\hline Yes & 89 & 67.4 & 244 & 92.4 & 0.000 \\
No & 21 & 15.9 & 17 & 6.4 & \\
Unknown & 22 & 16.7 & 3 & 1.2 & \\
Total & 132 & 100 & 264 & 100 \\
\hline
\end{tabular}

${ }^{*}$ Cases of abortion included.

Table 8. Maternal mortality and employment status.

\begin{tabular}{ccccc}
\hline Employment status & Cases & $\%$ & Reference population & p-value \\
Employed & 62 & 47 & 164 & 0.0005 \\
Unemployed & 59 & 44.7 & 96 & 4 \\
Unknown & 11 & 8.3 & 264 & 1.5 \\
Total & 132 & 100 & 264 & 100 \\
\hline
\end{tabular}

Seventy eight (59.1\%) of the women who died were married, 191 (72.3\%) of the reference population were also married. The relationship between maternal mortality and marital status was statistically significant, Table 5 .

The level of education was not known for all the cases in LRH, as this was not included in the identification section in the case notes. Twenty one percent of women who died in Tiko Cottage Hospital had primary education. The relationship between marital status and maternal mortality was not statistically significant, Table 6.

ANC attendance was considered irrespective of the number of antenatal visits she attended. Most of the cases 89 (67.4\%) attended ANC. A woman was considered to have had ANC even if she came for ANC once. Not haven't had antenatal care was significantly associated with maternal death, Table 7.

Most of the women were employed 62 (47\%) cases and $164(62.1 \%)$ of the reference population. The women were mainly hair dressers, traders and laborers. The unemployed were mainly housewives and students, Table 8.

The highest number of deaths occurred post partum (43.9\%), followed by ante partum deaths that were $26.8 \%$, Figure 2.

Only 18 cases $(14.6 \%)$ of the total number of maternal deaths had no associated factor and could be considered unavoidable. The non-availability of blood alone was responsible for $29.7 \%$ of all maternal deaths. While delay in arriving hospital for $19.8 \%$ of deaths. Though partogram were available and were supposed to be used in the management of patients in labor, this important instrument of decision was not used in all cases that culminated in maternal deaths (Table 9, Table 10). 


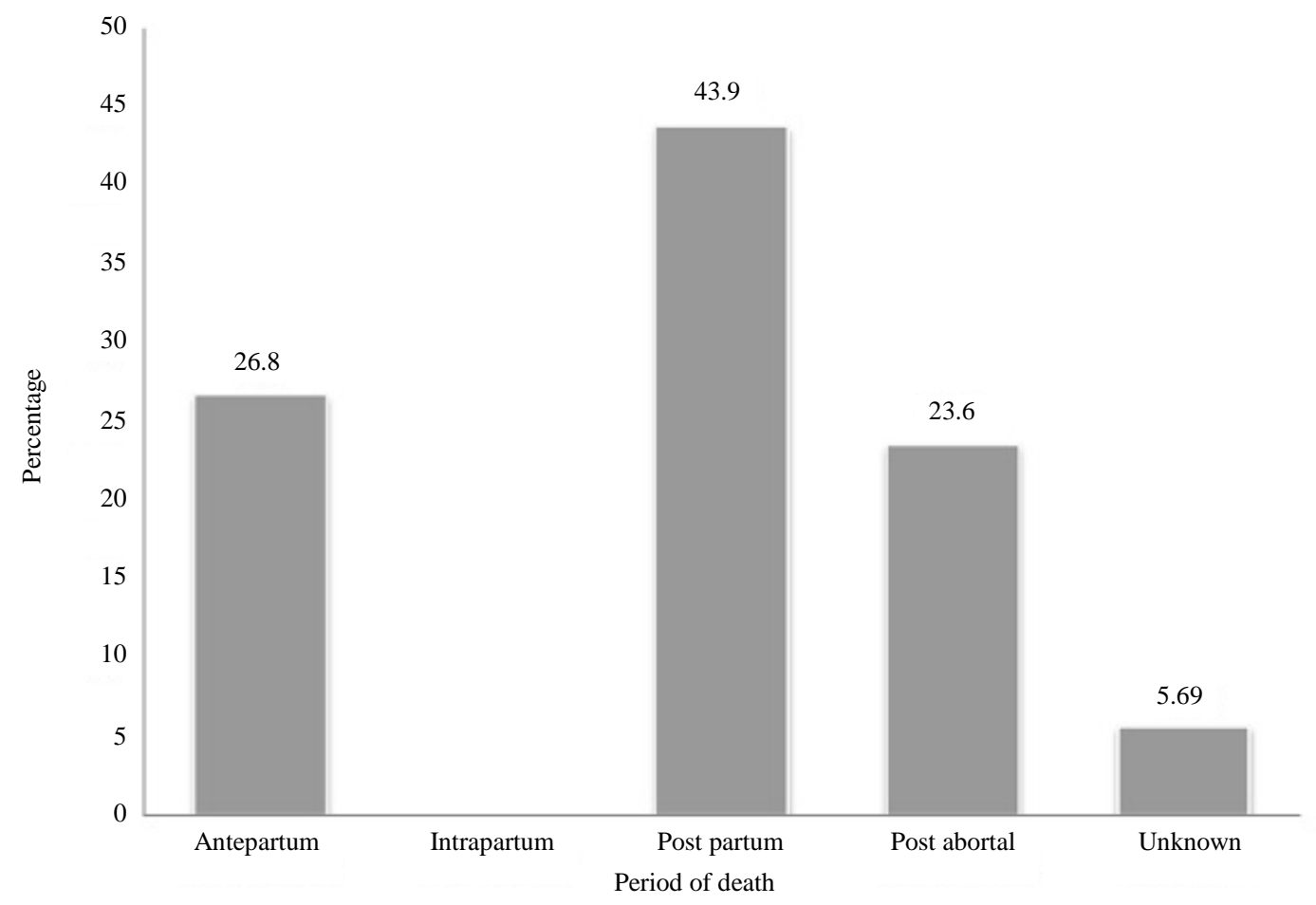

Figure 2. The period during which death occurred is highlighted.

Table 9. Logistic regression model for potential socio-demographic and obstetric characteristics influencing maternal mortality.

\begin{tabular}{|c|c|c|c|c|}
\hline \multirow{2}{*}{ Variables } & \multicolumn{2}{|c|}{ Bivariate } & \multicolumn{2}{|c|}{ Multivariate } \\
\hline & OR (CI) & p-value & OR (CI) & p-value \\
\hline \multicolumn{5}{|l|}{ Age } \\
\hline $25-29^{*}$ & 1 & - & 1 & - \\
\hline$(15-19 / 25$ - 29) & $1.14(0.18-2.49)$ & 0.0013 & $1.01(0.06-2.74)$ & 0.006 \\
\hline$(20-24 / 25-29)$ & $0.13(0.04-0.39)$ & 0.0003 & $0.16(0.05-0.053)$ & 0.002 \\
\hline$(30-34 / 25-29)$ & $0.19(0.06-0.60)$ & 0.004 & $0.25(0.07-0.88)$ & 0.030 \\
\hline$(35-39 / 25-29$ & $5.34(0.31-44.1)$ & 0.040 & $4.18(0.36-49.7)$ & 0.092 \\
\hline$(40-44 / 25-29)$ & $0.10(0.02-0.46)$ & 0.370 & $0.07(0.01-0.37)$ & 0.002 \\
\hline \multicolumn{5}{|l|}{ Marital Status } \\
\hline Married $^{*}$ & 1 & - & 1 & - \\
\hline Unmarried & $1.41(0.88-2.26)$ & 0.152 & $1.20(0.76-2.06)$ & 0.510 \\
\hline \multicolumn{5}{|l|}{ Employment Status } \\
\hline Employed ${ }^{*}$ & 1 & - & 1 & - \\
\hline Unemployed & $1.62(1.03-1.24)$ & 0.003 & $1.52(1.38-48.3)$ & 0.021 \\
\hline \multicolumn{5}{|l|}{ Parity } \\
\hline $\mathbf{1}^{*}$ & 1 & - & 1 & - \\
\hline Parity (2 - 4/1) & $0.35(0.11-0.62)$ & 0.004 & $0.35(0.11-1.19)$ & 0.074 \\
\hline Parity (>5/1) & $1.21(0.30-1.84)$ & 0.350 & $1.21(0.30-4.86)$ & 0.790 \\
\hline
\end{tabular}

*Groups used as reference. Age: The 15 - 19 years was used as a reference, and when compared with other age groups; with the age group of 35 - 29 years for example, there was a difference in odd ratio (OR) 4.3 [95\% CI ( 0.36 - 49.7); p-value $=0.092$ ]. This implies women 35 - 39 years were 4.3 times more likely to have maternal deaths than those of the 15 - 19 years age group. Marital status: The difference between married and unmarried women was an odd ratio of 1.20 [95\% CI (0.70 - 2.09); p-value $=0.51$ ]. Married women were 1.2 times more likely to die than unmarried women but the difference was not significant. Employment: Unemployed women were 1.5 times more likely to die compared to employed women. The difference was significant at 95\% CI (1.40 - 48.28); p-value = 0.002. Parity: Between Para 1 and more than Para 5, the OR was 1.2 but not statistically significant (p-value $=0.79)$. 
Table 10. Avoidable factors in relation to maternal death.

\begin{tabular}{|c|c|c|}
\hline Factors & Number of times & $\%$ \\
\hline \multicolumn{3}{|l|}{ Patient factor: } \\
\hline Delay in arriving hospital & 34 & 19.8 \\
\hline Induced abortion & 20 & 11.6 \\
\hline Refusal of medical advice & 7 & 4.07 \\
\hline \multicolumn{3}{|l|}{ Peripheral hospital: } \\
\hline No staff & 2 & 1.2 \\
\hline Late transfer & 31 & 18.0 \\
\hline Insufficient information on case & 1 & 0.6 \\
\hline \multicolumn{3}{|l|}{ Central hospital: } \\
\hline No doctor & 9 & 5.23 \\
\hline No equipment, drug, reagent & 9 & 5.23 \\
\hline No blood & 51 & 29.7 \\
\hline Total & $172^{*}(100)$ & \\
\hline
\end{tabular}

*Some cases had more than one avoidable factor.

\section{Discussion}

The maternal mortality ratio at the Tiko Cottage Hospital (TCH) and Limbe Regional Hospital (LRH) of 892 per 100,000 live births during the study period was high. However, this was slightly lower than 1000 per 100 , 0000 live births estimated by UNICEF for Cameroon 2000-2008 [9]. The ratio is high, compared to those of similar studies carried out in the same region 24 years ago by Mefany et al. [11], in other parts of Cameroon and high income countries [12] [13]. Higher MMR than those obtained in our study have been reported in Maroua, Cameroon by Tebeu et al. [7], Fomulu et al. [14] and Agan et al., in Calabar, Nigeria [15].

The high MMR recorded in the LRH and TCH can be explained by the fact that these hospitals deal with high-risk obstetric cases as they serve as the main referral centers for all the health centers, district hospitals as well as private hospitals of the Fako Division. Fifty four percentage of our cases were referred, a good proportion of which were moribund. The absence of blood for transfusion and essential drugs could be another reason for the high MMR we found in our study.

The very low level of MMR at the University of Yaoundé teaching hospital [13] was obtained by combining antepartum, intrapartum, and postpartum family planning components and by a rational deployment of personnel and restricted resources [16]. The same strategy, including the use of partograms could be applied in LRH and TCH to improve on MMR. The MMR reported in our study might be underestimated, as cases of deaths that occurred post partum after discharge from the hospital were not taken into consideration. Some pregnant women who died in other wards were probably not recorded as pregnancy related deaths. More accurate data would have been gotten from a community bases study in Fako Division.

With regards to the trends in maternal mortality ratio, though there were marked yearly variations from 283.9 to 1543.2 per 100,000 live births, there was a decline in the MMR during the period of study. This could be attributed to the recruitment of health personnel in hospitals [17], the renovation of the Buea regional hospital annex, improvement in the road infrastructure, provision of ambulance service and refresher courses in management of emergency obstetric cases. Despite all these, the decline is not significant to lead to the attainment of MDG 5 by 2015.

Post-partum hemorrhage (PPH), abortion and eclampsia were the leading causes of maternal deaths. Similar results were obtained in Accra by Yacoubo et al. [18], and Gabriel et al. [19] in Koforidua, Ghana. In these studies, PPH was the most common cause of maternal death unlike Tebeu et al. [7] in Maroua and Fomulu et al. [12] in Yaoundé General Hospital where hypertensive disorders in pregnancy accounted for most of the maternal deaths. The pattern of PPH, abortion and eclampsia could be due to the fact that there is inadequate awareness and practice of evidence based health interventions such as, the use of Magnesium sulphate for managing eclampsia, active management of the third stage of labour, etc. as stated by Tita et al. [20]. Also, the non-avail- 
ability of blood for transfusion played an important contributory role in causing maternal deaths as patients despite their critical state were often requested to provide blood donors.

The contraceptive use prevalence for Cameroon was reported to be $29 \%$ from 2000-2005 [9]. The low contraceptive prevalence probably accounted for the high number of abortions and their associated mortality. HIV complications were the leading indirect causes, findings similar to those of Tebeu et al. [7], and Agan et al. [15]. In African countries like South Africa and Zimbabwe, the increase in HIV prevalence has reversed the gains in reducing maternal mortality [4]. Only $14.6 \%$ of maternal deaths were unavoidable, with the lack of blood being the most common avoidable cause of death. This high percentage of avoidable maternal deaths in our study is in conformity with other studies. Agan et al. [15], Mafany et al. [11] and Parabhath et al. [21] in Shri Lanka.

In this study the relationship between MMR and ANC status was significant. A total, of $67.4 \%$ of the cases had antenatal care, though in $16.7 \%$ of the cases, the booking status was not known. These findings are similar to those of Mafany et al. [11] and Ujah et al. [22]; however, Agan et al. [15] had lower number of patients who were offered some form of ANC. Though, 89 (67.4\%) of cases supposedly had antenatal care, the high MMR in our study probably reflects the poor quality of ANC.

Most of the women 95 (72\%) who died were 20 - 34 years, with a peak of deaths in 25 - 29 age group. Similar high maternal mortality ratios were found in the same age group of patients by other authors [11] [12] [15] [19] [23] [24]. In our study we found that the age group 20 - 30 is the peak period for procreation, so most deaths are expected to fall in this group. Teenagers made up $12 \%$ of the women who died. This percentage is lower than the 28.6\% reported by Tebeu et al. [23] in Maroua, Cameroon. This was probably due to the higher proportion of educated females, and low level of early marriages in our study population.

Maternal deaths occurred mainly with primiparous 48 (36.4\%), after the second delivery 22 (16.7\%) and grand multiparous 17 (12.8\%) women. This finding is similar to those of Ujab et al. [22] in Nigeria where primiparous women died more in 32\% of cases, Tebeu et al. [23] in Maroua, Cameroon and Eghe et al. [24] in Benin, Nigeria also documented more deaths in nulliparous women. Nkwabong et al. [25] showed that poor obstetric outcome was common amongst primips who were more than 25 years. Loudon [26] investigated the relationship between age and parity, and showed that for all ages, there was a higher risk of maternal death in first births than in second or third. Grand multiparous patients also had a high risk of dying in this study. These results are similar to those of Mbassi et al. [27].

Fifty-nine percent of women who died were married, while $31.8 \%$ were not. The risk of maternal death though not statistically significant was higher in married women [OR $=1.20 ; 95 \%$ CI: $(0.70-2.07) ; \mathrm{p}=0.508]$. This finding was similar to that obtained by Agan et al. [15] in Nigeria and Tebeu et al. [23], Fomulu et al. [12], Fomulu et al. [28] in Cameroon. However, Mafany et al. [11] in a study carried out in the same region had more deaths amongst unmarried women. His explanation was that single women had less support so they presented with more complications related to pregnancy. The higher death toll seen married couples in our study is linked to predisposition for couples to have many children thus constituting a higher proportion of the women who came for delivery.

Unlike in Mafany et al. [11] study where 53.3\% of cases had no formal education. All parturients in our study were the educational status was documented were educated, though as much as $23.3 \%$ had but primary education. We could not critically assess the influence of educational status on maternal death in our study because this status was not specified in a large number of cases. The occupational status did not also correlate with the level of education as forty- percent of cases were employed and $45 \%$ unemployed.

The unemployed were more at risk of maternal death [OR $=1.52$; 95\% CI: $(1.38-48.28) ; \mathrm{p}=0.02$ ]. This tendency was also reported by Tiomela et al. [29] and Agan et al. [15] studies where 76\% and 55\% of cases were unemployed women respectively. This is evident due to the fact that these groups of women have no source of income and so were likely to delay in seeking good quality medical care.

\section{Conclusion}

The maternal mortality ratio of 892 per 100,000 in TCH and LRH which are the referral centres that are supposed to provide good obstetric care in this region is high. The triad- $\mathrm{PPH}$, abortion and eclampsia is still responsible for most of the maternal deaths though other indirect causes like complications of HIV infections and hepatitis are gradually becoming important in worsening death toll. The majority of the maternal deaths were preventable that notwithstanding there was no appreciable decline in the MMR during the period of study. De- 
spite the limitation of the study like lack of certain information because of poor records and no postmortem examination for specific diagnosis, it is glaring that with barely three years to 2015, the attainment of MDG 5 in this region looks utopic. We recommend that there should be amelioration towards obstetric emergencies care and health education by health care providers for there is hope of considerably reducing the high maternal mortality in this region.

\section{Authors Contribution}

Gregory Halle Ekane contributed in the project conception, analysis and interpretation of data, writing of the manuscript and is the corresponding author. Thomas Egbe Obinchemti contributed in data analysis and interpretation and proof read the manuscript. Lydia Kahgomia Fokunang contributed in designing the research, collection, analysis and interpretation of data and drafting of the article Theophile Nana Djamen and Charlotte Nguefack Tchente did part of the data analysis and proof read the manuscript. Martin Njie Mafany and Ndemazie Nkafu Bechem participated in the research conception, data analysis and interpretation and proof read of the manuscript. Daniel Lantum contributed in designing the research, analysis and interpretation of data and drafting of the article and proof read the manuscript.

\section{Acknowledgements}

This study was made possible by the administrative authorities of the Limbe Regional and the Tiko Cottage hospitals who accepted that we should exploit the medical records of the deceased pregnant women. We wish to thank Dr. Morike Ngoe Mokube and Dr. Betrand Hugo Mbatchou who initially reviewed the manuscript. We are also highly indebted to some of my classmates for helping us sort the relevant medical records.

\section{References}

[1] Rosenfield, A. and Maine, D. (1987) Maternal Health in Third World. Lancet, 1, 691-197. http://dx.doi.org/10.1016/S0140-6736(87)90461-2

[2] Hill, K., AbouZahr, C. and Wardlaw, T. (2001) Estimates of Maternal Mortality for 1995. Bulletin of World Health Organization, 79, 182-193.

[3] Priya, A. and Van Den Broek, N. (2009) Priorities in Obstetrics and Gynaecology in the Developing World Obstetrics. Gynaecology and Reproductive Medicine, 19, 197-200. http://dx.doi.org/10.1016/j.ogrm.2009.03.006

[4] Carine, R., Wendy, J. and Graham, D. (2006) Maternal Mortality: Who, When, Where, and Why. The Lancet, 368, 1189-1200. http://dx.doi.org/10.1016/S0140-6736(06)69380-X

[5] United Nations (2010) United Nations Millennium Development Goal Report. United Nations, New York.

[6] FMSB (1997) Nkigoum. Mortalite Maternelle au CHU de Yaounde: Etude Retrospective de 1988-1997. These de Doctorat en Medecine, FMSB, Yaounde.

[7] Tebeu, P.M., Ngassa, P., Kouam, L., Major, A.L. and Fomulu, J.N. (2007) Maternal Mortality in Maroua Provincial Hospital, Cameroon (2003-2005). West Indian Medical Journal, 56, 502.

[8] United Nations (2011) Millennium Development Goal Report. United Nations, New York.

[9] United Nations Children Fund (UNICEF) (2010) The State of World Children: Maternal and New Born Health. United Nations, New York.

[10] World Health Organization (1993) International Statistical Classification of Diseases and Related Health Problems. 10th Revision, WHO, Geneva.

[11] Mafany, N., Mati, J.K.G. and Nasah, B.T. (1990) Maternal Mortality in South West Region Cameroon (1982-1987). Annales Universitaire de Sante, CUSS Yaounde, 7, 52-59.

[12] Fomulu, J.N., Tchana, T.M., Nana, N.P., Mbu, R. and Kasia, J.M. (2008) Mortalité maternelle à l’hôpital général de Yaoundé: Etude rétrospective sur 5 années (2002-2006). Health Sciences and Disease, 10, 86-92.

[13] Doh, A.S., Nasah, B.T. and Kamdom-Moyo, J. (1991) The Outcome of Labor at the University Teaching Hospital (CHU), Yaoundé, Cameroon. International Journal of Gynecology and Obstetrics, 36, 195-201.

[14] Fomulu, J.N., Tiyou, K.C., Mbu, R.E., Nana, N.P. and Leke, R.J. (2009) Mortalité maternelle à la Maternité Principale de Yaoundé: Etude rétrospective de 2001 à 2006. Health Sciences and Disease, 9, 5-10.

[15] Agan, T.U., Archibong, E.I., Ekabua, J.E., Ekanem, E.I., Abeshi, S.E., Edentekhe, T.A. and Bassey, E. (2010) Tends in Maternal Mortality in the Calabar Teaching Hospital, Nigeria 1999-2009. International Journal of Women's Health, 2, 
249-245.

[16] Nasah, B.T., Leke, R.J., Doh, A.S., Moyo, J.K., Fomulu, J. and Njikam, O.M. (1999) The Risk Approach for Reducing Maternal Mortality: The Yaoundé Experience. International Journal of Gynecology \& Obstetrics, 13, 195-201.

[17] Ministry of Public Health (2006) Advocacy for Education of Maternal Mortality in Cameroon. UNFPA, Yaounde.

[18] Zakariah, A.Y., Alexander, S., Van Roosmalen, J., Buekens, P., Kwawukume, E.Y. and Frimpong, P. (2009) Reproductive Age Mortality Survey (RAMOS) in Accra, Ghana. Reproductive Health, 6, 7.

[19] Gabriel, Y.K., Ganyaglo, M.G. and Hill, W.C. (2012) A 6-Year (2004-2009) Review of Maternal Mortality at the Eastern Regional Hospital, Koforidua, Ghana. Seminars in Perinatology, 36, 79-83. http://dx.doi.org/10.1053/j.semperi.2011.09.015

[20] Tita, A.T., Selwyn, B.J., Waller, D.K., Kapadia, A.S. and Dongmo, S. (2005) Evidence-Based Reproductive Health Care in Cameroon: Population-Based Study of Awareness, Use and Barriers. Bulletin of the World Health Organization, 83, 895-903.

[21] Wagaarachchi, P.T. and Fernando, L. (2002) Trends in Maternal Mortality and Assessment of Sub Standard Care in a Tertiary Care Hospital. European Journal of Gynecology and Obstetrics, 58, 36-40.

[22] Ujah, I.A., Aisien, O.A., Mutihir, J.T., Vanderjagt, D.J., Glew, R.H. and Uguru, V.E. (2005) Factors Contributing to Maternal Mortality in North-Central Nigeria: A Seventeen-Year Review. African Journal of Reproductive Health, 9, 24-27. http://dx.doi.org/10.2307/3583409

[23] Tebeu, P.M., Foumane, P., Mbu, R., Fosso, G., Biyaga, P.T. and Fomulu, J.N. (2011) Risk Factors for Hypertensive Disorders in Pregnancy: A Report from the Maroua Regional Hospital, Cameroon. Journal of Reproduction and Infertility, 12, 227-234.

[24] Abe, E. and Omo-Aghoja, L.O. (2008) Maternal Mortality at the Central Hospital, Benin City Nigeria: A Ten Year Review. African Journal of Reproductive Health, 12, 17-26.

[25] Nkwabong, E., Fomulu, J.N., Hamida, V., Onana, A., Tjek, V., Kouam, V. and Ngassa, P. (2011) The Risk of Adverse Maternal and Neonatal Outcomes in Cameroonian Primiparous Women Aged More than 26 Years. Clinics in Mother and Child Health, 8, 1-4.

[26] Loudon, I. (1992) Death in Childbirth: An International Study of Maternal Care and Maternal Mortality 1800-1950. Oxford University Press, Oxford.

[27] Mbola Mbassi, S., Mbu, R. and Bouvier-Colle, M.H. (2009) Delay in the Management of Obstetric Complications: Study in 7 Maternity Units in Cameroon. Medicine Tropical, 69, 480-484.

[28] Fomulu, J.N., Ngassa, P.N., Nong, T., Nana, P. and Nkwabong, E. (2009) Mortalité maternelle à la Maternité du Centre Hospitalier et Universitaire de Yaoundé, Cameroun: Etude rétrospective de 5 ans (2002 à 2006). Health Sciences and Disease, 10, 11-16.

[29] Tiomela, P. (2003) Apprecier la Mortalite Maternelle a la Maternite Principale de Yaounde 5 ans apres sa Reorganisation. Sujet de Recherche d'obstetrique, Memoire de fin d'etudes speciales de Gynecologie et d'obstetrique, Yaounde. 
Scientific Research Publishing (SCIRP) is one of the largest Open Access journal publishers. It is currently publishing more than 200 open access, online, peer-reviewed journals covering a wide range of academic disciplines. SCIRP serves the worldwide academic communities and contributes to the progress and application of science with its publication.

Other selected journals from SCIRP are listed as below. Submit your manuscript to us via either submit@scirp.org or Online Submission Portal.
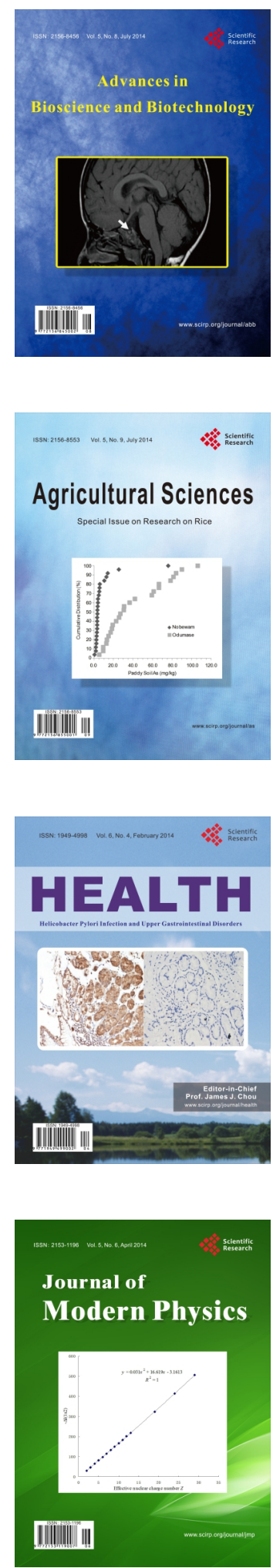
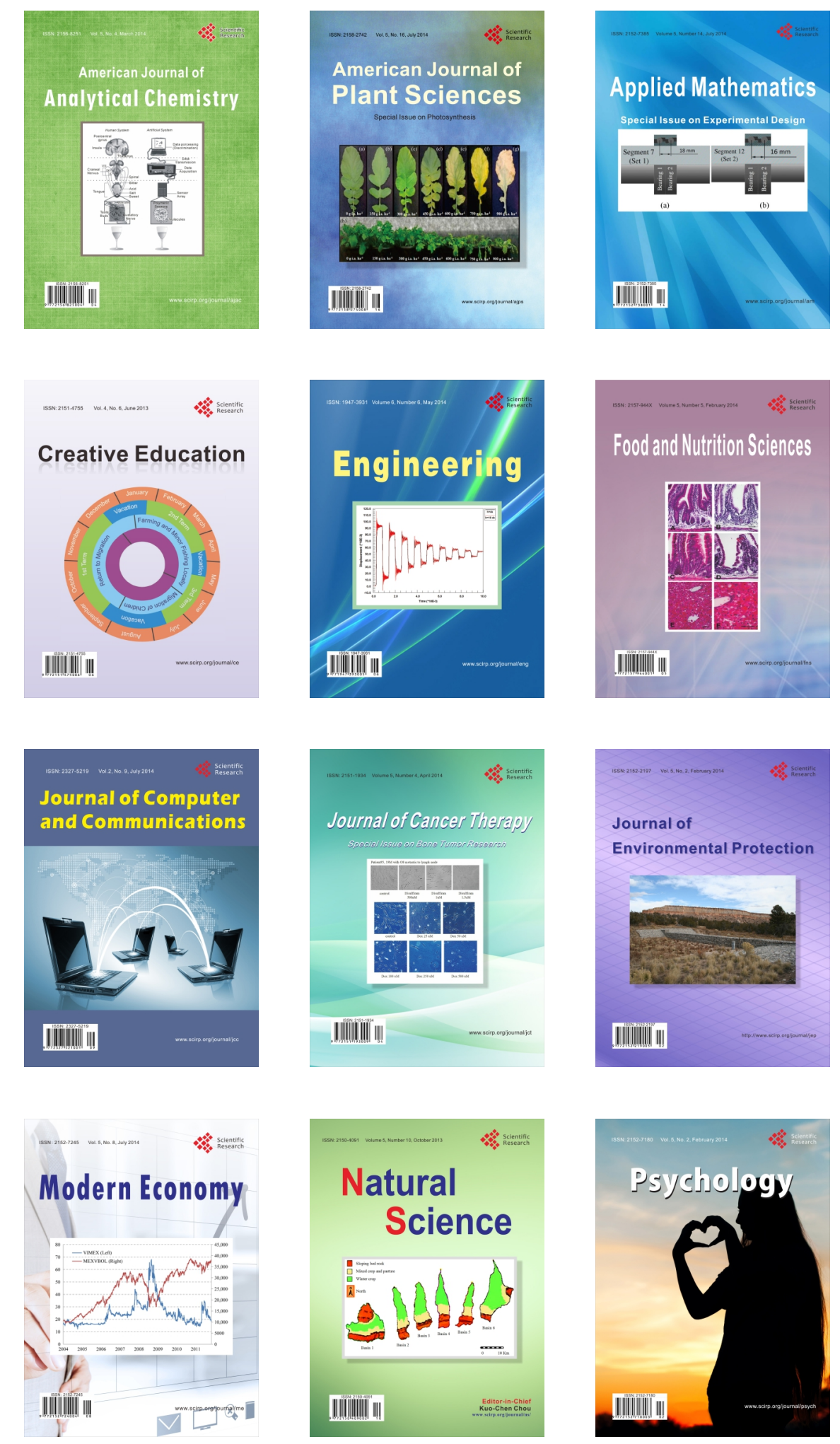